\title{
The next generation of obesity treatments: beyond suppressing appetite
}

\author{
Nicole M. Avena ${ }^{1,2 *}$, Susan Murray ${ }^{1,2}$ and Mark S. Gold ${ }^{1}$ \\ 1 Department of Psychiatry, University of Florida, Gainesville, FL, USA \\ ${ }^{2}$ Department of Psychology, Princeton University, Princeton, NJ, USA \\ ${ }^{*}$ Correspondence: navena@ufl.edu \\ Edited by: \\ Michael R. Lowe, Drexel University, USA
}

Keywords: obesity, appetite suppressants, food addiction, palatable food, animal models

Obesity remains a prominent public health concern in the United States as well as many other countries, with $33 \%$ of adults worldwide overweight or obese in 2005 and an estimated $60 \%$ by 2030 (Kelly et al., 2008). This data highlights the need for effective prevention and intervention strategies. Obesity can be viewed as an endpoint with many possible contributing factors, including genetic propensity, sedentary lifestyles, and the relative ease with which one can obtain food, particularly in modern industrialized societies. Such factors may result in an imbalance between the number of calories consumed vs. expended. The majority of pharmaceutical compounds that have been developed to combat obesity aim to correct or improve this last factor by suppressing appetite (See Table 1). However, the number of people with obesity in the United States does not appear to be decreasing (Flegal et al., 2012). Here we present some possible reasons why these drugs have failed to fully address the problem of obesity.

First, the weight loss associated with the appetite suppressant drugs on the market is not as dramatic as one might expect. For example, one drug which received FDA approval in 2012, Belviq, has been found to result in a mean weight loss of $3-3.6 \%$, corrected for the effects of placebo, in phase III clinical trials (Miller, 2013). Another recently approved drug, Qsymia, which consists of a combination of phentermine and extended-release topiramate, an anti-epileptic drug, has shown greater effects, producing a mean weight loss of between 7.5 and 9.3\%, corrected for the effects of placebo, during phase III clinical trials (Garvey, 2013). While these medications may be more or less effective for certain individuals, especially in light of other lifestyle changes, and these reductions are certainly beneficial, they do not appear to be the definitive weight loss interventions.

Second, suppressing appetite may be too simplistic of an approach. Instead of aiming to reduce intake of all types of foods, it may be more beneficial over the long term to specifically reduce excessive intake of foods rich in fats or sugars, which can contain excessive amounts of calories but offer minimal nutritional value. To our knowledge, no appetite suppressant on the market to date has been known to reduce intake of specific types of food. This approach may facilitate the normalization of eating patterns by decreasing overconsumption of less healthy options without affecting intake of sources of greater nutrition. Further, recent research suggests that the age old adage "a calorie is a calorie" is not exactly true. Not all calories are created equal. For example, research has found that there are differences in the effects of equicaloric diets comprised of different proportions of macronutrients (Ebbeling et al., 2012). Resting and total energy expenditure has been shown, for instance, to be most decreased in response to a low-fat diet, compared to low glycemic index and low carbohydrate diets, without differences in physical activity, suggesting that diets consisting of varying macronutrient compositions can differentially affect one's metabolism. Further, this finding supports the hypothesis that targeted pharmacotherapy may be beneficial.

It is also possible that appetite suppressants may not have worked well for obesity because these medications have targeted appetite in general, rather than targeting the mechanisms of reinforcement associated with food intake, as has been initiated in the past with the endocannabinoid system (Carai et al., 2006). Targeting neural reward systems may also, in turn, result in a selective suppression of appetite for certain types of highly reinforcing foods. Findings from our laboratory and others have revealed that overconsumption, or binge consumption, of sugars and fats can lead to brain and behavioral changes similar to those seen within the context of drug addiction, providing empirical support for the concept of food addiction (Avena et al., 2008; Oswald et al., 2011; Iemolo et al., 2012; Rossetti et al., 2013). Such findings point to one potential reason that weight loss may be so challenging for some, but also provide an avenue to study potential treatments that consider and address the effects that these ingredients can have on the brain. In light of the similarities between binge intake of highly palatable foods and drug addiction, our laboratory and others have been interested in studying the effects of medications that have been used to treat substance use disorders on overeating. For example, the GABA-B agonist, baclofen, which has been found to be effective in treating several aspects of alcohol dependence in many (Addolorato et al., 2000, 2007, 2011) but not all studies (Garbutt et al., 2010), has also been shown to aid in the reduction of binge eating behavior in both preclinical and clinical studies (Buda-Levin et al., 2005; Broft et al., 2007; Berner et al., 2009; Corwin et al., 2012). Additionally, baclofen has shown some success in inhibiting weight gain in animals and promoting weight loss in clinical samples (Sato et al., 2007; Arima and Oiso, 2010; Patel and Ebenezer, 2010). 
Table 1 | Current pharmaceutical treatments of obesity.

\begin{tabular}{|c|c|c|c|}
\hline Name & Approved & Type of compound & Proposed mechanism of action \\
\hline Phentermine & 1959 & Sympathomimetic amine & Appetite suppressant \\
\hline Fenfluramine* ${ }^{*}$ Dexfenfluramine* & & Serotonergic agent & Appetite suppressant \\
\hline Benzphetamine & & Sympathomimetic amine & Appetite suppressant \\
\hline Phendimetrazine & 1979 & Sympathomimetic amine & Appetite suppressant \\
\hline Diethylpropion & & Sympathomimetic amine & Appetite suppressant \\
\hline Sibutramine* & 1997 & $\begin{array}{l}\text { Noradrenaline and serotonin reuptake } \\
\text { inhibitor }\end{array}$ & $\begin{array}{l}\text { Appetite suppressant (also } \\
\text { stimulates thermogenesis) }\end{array}$ \\
\hline Orlistat & 1999 & Lipase inhibitor & Inhibits the absorption of dietary fat \\
\hline Phentermine/Topiramate & 2012 & $\begin{array}{l}\text { Sympathomimetic } \\
\text { amine/sulfamate-substituted monosaccharide }\end{array}$ & Appetite suppressant \\
\hline Lorcaserin & 2012 & Selective serotonin $2 \mathrm{C}$ receptor agonist & Appetite suppressant \\
\hline
\end{tabular}

${ }^{*}$ Removed from the market.

Using the food addiction model in the laboratory may be an innovative approach to identifying potential weight loss treatments which take into account the neurochemical effects of regularly overeating certain macronutrients. In clinical samples, $25 \%$ of participants who are obese meet the diagnostic criteria for "food addiction," according to the Yale Food Addiction Scale (YFAS) (Davis et al., 2011). Studies assessing obese individuals with binge eating disorder have found that $42-57 \%$ participants meet this criteria (Gearhardt et al., 2012, 2013), and the percentage of obese individuals seeking bariatric surgery who meet this criteria is $42 \%$ (Meule et al., 2012). Thus, while not all individuals who are obese express addiction-like characteristics or behaviors regarding food, there are a significant number of individuals who do, and who may thus benefit from addiction-targeting treatments. One avenue for this research includes the study of medications that have been successful in treating substance use disorders (Gold and Avena, 2013). With redefined goals in mind, including a greater focus on the reduction of overeating specific foods, such research may lead to the development of more targeted weight loss treatments.

\section{ACKNOWLEDGMENTS}

Supported by DA-03123 (Nicole M. Avena) and Kildehoj Santini (Nicole M. Avena).

\section{REFERENCES}

Addolorato, G., Caputo, F., Capristo, E., Colombo, G., Gessa, G. L., and Gasbarrini, G. (2000).
Ability of baclofen in reducing alcohol craving and intake: II-Preliminary clinical evidence. Alcohol. Clin. Exp. Res. 24 67-71.

Addolorato, G., Leggio, L., Ferrulli, A., Cardone, S., Bedogni, G., Caputo, F., et al. (2011). Doseresponse effect of baclofen in reducing daily alcohol intake in alcohol dependence: secondary analysis of a randomized, double-blind, placebocontrolled trial. Alcohol Alcohol. 46, 312-317. doi: 10.1093/alcalc/agr017

Addolorato, G., Leggio, L., Ferrulli, A., Cardone, S., Vonghia, L., Mirijello, A., et al. (2007). Effectiveness and safety of baclofen for maintenance of alcohol abstinence in alcohol-dependent patients with liver cirrhosis: randomised, doubleblind controlled study. Lancet 370, 1915-1922. doi: 10.1016/S0140-6736(07)61814-5

Arima, H., and Oiso, Y. (2010). Positive effect of baclofen on body weight reduction in obese subjects: a pilot study. Intern. Med. 49, 2043-2047. doi: 10.2169/internalmedicine.49.3918

Avena, N. M., Rada, P., and Hoebel, B. G. (2008) Evidence for sugar addiction: behavioral and neurochemical effects of intermittent, excessive sugar intake. Neurosci. Biobehav. Rev. 32, 20-39. doi: 10.1016/j.neubiorev.2007.04.019

Berner, L. A., Bocarsly, M. E., Hoebel, B. G., and Avena, N. M. (2009). Baclofen suppresses binge eating of pure fat but not a sugar-rich or sweetfat diet. Behav. Pharmacol. 20, 631-634. doi: 10.1097/FBP.0b013e328331ba47

Broft, A. I., Spanos, A., Corwin, R. L., Mayer, L., Steinglass, J., Devlin, M. J., et al. (2007). Baclofen for binge eating: an open-label trial. Int. J. Eat. Disord. 40, 687-691. doi: 10.1002/eat.20434

Buda-Levin, A., Wojnicki, F. H., and Corwin, R. L. (2005). Baclofen reduces fat intake under bingetype conditions. Physiol. Behav. 86, 176-184. doi: 10.1016/j.physbeh.2005.07.020

Carai, M. A., Colombo, G., Maccioni, P., and Gessa, G. L. (2006). Efficacy of rimonabant and other cannabinoid $\mathrm{CB} 1$ receptor antagonists in reducing food intake and body weight: preclinical and clinical data. CNS Drug Rev.12, 91-99. doi: 10.1111/j.1527-3458.2006.00091.x

Corwin, R. L., Boan, J., Peters, K. F., and Ulbrecht, J. S. (2012). Baclofen reduces binge eating in a double-blind, placebo-controlled, crossover study. Behav. Pharmacol. 23, 616-625. doi: 10.1097/FBP.0b013e328357bd62

Davis, C., Curtis, C., Levitan, R. D., Carter, J. C., Kaplan, A. S., and Kennedy, J. L. (2011). Evidence that 'food addiction' is a valid phenotype of obesity. Appetite 57, 711-717. doi: 10.1016/j.appet.2011.08.017

Ebbeling, C. B., Swain, J. F., Feldman, H. A., Wong, W. W., Hachey, D. L., Garcia-Lago, E., et al. (2012). Effects of dietary composition on energy expenditure during weight-loss maintenance. JAMA 307, 2627-2634. doi: 10.1001/jama. 2012.6607

Flegal, K. M., Carroll, M. D., Kit, B. K., and Ogden, C. L. (2012). Prevalence of obesity and trends in the distribution of body mass index among US adults, 1999-2010. JAMA 307, 491-497. doi: 10.1001/jama.2012.39

Garbutt, J. C., Kampov-Polevoy, A. B., Gallop, R., Kalka-Juhl, L., and Flannery, B. A. (2010). Efficacy and safety of baclofen for alcohol dependence: a randomized, double-blind, placebo-controlled trial. Alcohol. Clin. Exp. Res. 34, 1849-1857. doi: 10.1111/j.1530-0277.2010.01273.x

Garvey, W. T. (2013). Phentermine and topiramate extended-release: a new treatment for obesity and its role in a complications-centric approach to obesity medical management. Expert Opin. Drug Saf. 12, 741-756. doi: 10.1517/14740338.2013.806481

Gearhardt, A. N., White, M. A., Masheb, R. M., and Grilo, C. M. (2013). An examination of food addiction in a racially diverse sample of obese patients with binge eating disorder in primary care settings. Compr. Psychiatry 54, 500-505. doi: 10.1016/j.comppsych.2012.12.009

Gearhardt, A. N., White, M. A., Masheb, R. M., Morgan, P. T., Crosby, R. D., and Grilo, C. M. (2012). An examination of the food addiction construct in obese patients with binge eating disorder. Int. J. Eat. Disord. 45, 657-663. doi: 10.1002/eat.20957

Gold, M. S., and Avena, N. M. (2013). Animal models lead the way to further understanding food addiction as well as providing evidence that drugs used successfully in addictions can be successful in treating overeating. Biol. Psychiatry 74:e11. doi: 10.1016/j.biopsych.2013.04.022 
Iemolo, A., Valenza, M., Tozier, L., Knapp, C. M., Kornetsky, C., Steardo, L., et al. (2012). Withdrawal from chronic, intermittent access to a highly palatable food induces depressive-like behavior in compulsive eating rats. Behav. Pharmacol. 23, 593-602. doi: 10.1097/FBP.0b013e328357697f.

Kelly, T., Yang, W., Chen, C. S., Reynolds, K., and He, J. (2008). Global burden of obesity in 2005 and projections to 2030. Int. J. Obes. (Lond.) 32, 1431-1437. doi: 10.1038/ijo. 2008.102

Meule, A., Heckel, D., and Kubler, A. (2012). Factor structure and item analysis of the Yale Food Addiction Scale in obese candidates for bariatric surgery. Eur. Eat. Disord. Rev. 20, 419-422. doi: 10.1002/erv. 2189

Miller, L. E. (2013). Lorcaserin for weight loss: insights into US Food and Drug Administration approval. J. Acad. Nutr. Diet. 113, 25-30. doi: 10.1016/j.jand.2012.08.028
Oswald, K. D., Murdaugh, D. L., King, V. L., and Boggiano, M. M. (2011). Motivation for palatable food despite consequences in an animal model of binge eating. Int. J. Eat. Disord. 44, 203-211. doi: 10.1002/eat.20808

Patel, S. M., and Ebenezer, I. S. (2010). Effects of chronic systemic administration of the $\mathrm{GABA}(\mathrm{B})$ receptor agonist baclofen on food intake and body weight in rats. Eur. J. Pharmacol. 635, 129-134. doi: 10.1016/j.ejphar.2010. 03.014 .

Rossetti, C., Spena, G., Halfon, O., and Boutrel, B. (2013). Evidence for a compulsive-like behavior in rats exposed to alternate access to highly preferred palatable food. Addict. Biol. doi: 10.1111/ adb.12065. [Epub ahead of print].

Sato, I., Arima, H., Ozaki, N., Ozaki, N., Watanabe, M., Goto, M., et al. (2007) Peripherally administered baclofen reduced food intake and body weight in $\mathrm{db} / \mathrm{db}$ as well as diet-induced obese mice. FEBS Lett.
581, 4857-4864. doi: 10.1016/j.febslet.2007. 09.011

Received: 13 July 2013; accepted: 19 September 2013; published online: 09 October 2013.

Citation: Avena NM, Murray S and Gold MS (2013)

The next generation of obesity treatments: beyond suppressing appetite. Front. Psychol. 4:721. doi: 10.3389/ fpsyg.2013.00721

This article was submitted to Eating Behavior, a section of the journal Frontiers in Psychology.

Copyright (c) 2013 Avena, Murray and Gold. This is an open-access article distributed under the terms of the Creative Commons Attribution License (CC BY). The use, distribution or reproduction in other forums is permitted, provided the original author(s) or licensor are credited and that the original publication in this journal is cited, in accordance with accepted academic practice. No use, distribution or reproduction is permitted which does not comply with these terms. 